Распространенность аллергической и неаллергической бронхиальной астмы и спектр сенсибилизации среди детей дошкольного возраста, проживающих в городских условиях Алтайского края: популяционное одномоментное исследование

\author{
Н.В. Шахова ${ }^{1}$ Е.М. Камалтынова ${ }^{2}$ Ю.Ф. Лобанов ${ }^{1}$, Т.С. Кашинская ${ }^{1}$ \\ 'ФГБОУ ВО «Алтайский государственный медицинский университет», Минздрава России, Барнаул, Россия; \\ ФГБОУ ВО «Сибирский государственный медицинский университет», Минздрава России, Томск, Россия
}

\title{
The prevalence of allergic and non-allergic bronchial asthma and the spectrum of sensitization among children of preschool age living in urban areas of the Altai Territory: a momentary population study
}

\author{
N.V. Shakhova', E.M. Kamaltynova², Yu.F. Lobanov', T.S. Kashinskaya ${ }^{1}$ \\ ${ }^{1}$ Altai State Medical University, Barnaul, Russia; \\ ${ }^{2}$ Siberian State Medical University, Tomsk, Russia
}

\begin{abstract}
Информация о распространенности аллергической и неаллергической бронхиальной астмы среди детей дошкольного возраста ограничена в связи с недостаточным количеством исследований. В то же время определение фенотипа заболевания является ключевым для выбора оптимальной терапии и определения прогноза. Цель исследования: установить распространенность аллергической и неаллергической бронхиальной астмы у детей 3-6 лет, проживающих в городских условиях Алтайского края, и изучить спектр сенсибилизации.

Проведено одномоментное популяционное исследование, состоявшее из двух этапов. На этапе скрининга в исследование включены 3205 детей в возрасте 3-6 лет, посещающих дошкольные образовательные учреждения. Симптомы бронхиальной астмы определяли, используя опросник ISAAC. На клиническом этапе диагноз заболевания верифицировали аллергологи на основании диагностических критериев GINA. Аллергический фенотип бронхиальной астмы устанавливали при положительном прик-тесте и/или при уровне специфических IgE в крови >0,35 кЕ/л как минимум к одному аллергену.

Результаты. Распространенность бронхиальной астмы среди городских детей в возрасте 3-6 лет составила 5,7\%. Распространенность аллергической бронхиальной астмы преобладает над неаллергической - 4 и 1,7\% соответственно. Состояние большинства детей сенсибилизировано к 2 аллергенам и более, наиболее часто отмечается сенсибилизация к клещу домашней пыли Dermatophagoides pteronyssinus $(42,9 \%)$, пыльце березы $(34,3 \%)$ и эпителию кошки $(27,5 \%)$. Заключение. Установлена высокая $(5,7 \%)$ распространенность бронхиальной астмы среди детей 3-6 лет, проживающих в городских условиях Алтайского края с преобладанием аллергического фенотипа.
\end{abstract}

Ключевые слова: дети, дошкольный возраст, бронхиальная астма, фенотип, аллергены, сенсибилизация, Dermatophagoides pteronyssinus, пыльца березы, эпителий кошки.

Для цитирования: Шахова Н.В., Камалтынова Е.М., Лобанов Ю.Ф., Кашинская Т.С. Распространенность аллергической и неаллергической бронхиальной астмы и спектр сенсибилизации среди детей дошкольного возраста, проживающих в городских условиях Алтайского края: популяционное одномоментное исследование. Рос вестн перинатол и педиатр 2019; 64:(1): 88-93. DOI: 10.21508/1027-4065-2019-64-1-88-93

Information on the prevalence of allergic and non-allergic bronchial asthma among children of preschool age is limited due to insufficient amount of studies. At the same time, determining the phenotype of the disease is the key to choosing the optimal therapy and determining the prognosis.

The objective: to establish the prevalence of allergic and non-allergic bronchial asthma in children of 3-6 years living in the urban areas of the Altai Territory, and to study the sensitization spectrum. The authors conducted a momentary population-based study, consisting of two stages. At the screening stage, the study included 3205 children of 3-6 years attending preschool educational institutions. Symptoms of bronchial asthma were determined using the ISAAC questionnaire. At the clinical stage, the diagnosis was verified by allergists based on the diagnostic criteria of GINA. The allergic phenotype of asthma was established with a positive prick test and / or at a level of specific blood IgE of $>0.35 \mathrm{kE} / \mathrm{I}$ to at least one allergen.

The results. 5.7\% of urban children of 3-6 years suffered bronchial asthma. Allergic asthma prevails over non-allergic one -4 and $1.7 \%$, respectively. The condition of most children is sensitized to 2 allergens and more, the most often case was a sensitization to house dust mite Dermatophagoides pteronyssinus $(\mathbf{4 2 . 9 \% )}$ birch pollen $(34.3 \%)$ and cat epithelium $(27.5 \%)$.

The conclusion. 5.7\% of children of 3-6 years living the in urban areas of the Altai Territory suffered bronchial asthma with a predominance of allergic phenotype.

Key words: children, preschool age, bronchial asthma, phenotype, allergens, sensitization, Dermatophagoides pteronyssinus, birch pollen, cat epithelium.

For citation: Shakhova N.V., Kamaltynova E.M., Lobanov Yu.F., Kashinskaya T.S. The prevalence of allergic and non-allergic bronchial asthma and the spectrum of sensitization among children of preschool age living in urban areas of the Altai Territory: a momentary population study. Ros Vestn Perinatol i Pediatr 2019; 64:(1): 88-93 (in Russ). DOI: 10.21508/1027-4065-2019-64-1-88-93

() Коллектив авторов, 2019

Адрес для корреспонденции: Шахова Наталья Викторовна - к.м.н., доцент кафедры пропедевтики детских болезней Алтайского государственного медицинского университета, ORCID: 0000-0002-7143-8259 e-mail: natalia.shakhova@mail.ru

Лобанов Юрий Федорович - д.м.н., проф., зав. кафедрой пропедевтики детских болезней Алтайского государственного медицинского университета, ORCID: 0000-0001-7801-0223 
Кашинская Татьяна Сергеевна - асс. кафедры пропедевтики детских болезней Алтайского государственного медицинского университета, ORCID: 0000-0001-8184-9230

656038 Барнаул, пр. Ленина, д. 40

$\mathbf{b}^{\mathrm{p}}$ ронхиальная астма является одним из наиболее часто встречающихся хронических заболеваний, распространенность которого среди детского населения варьирует от 5 до 15\% [1, 2]. В 2008 г. Европейской академией аллергологии и клинической иммунологии совместно с Американской академией аллергии, астмы и иммунологии опубликован международный согласительный документ «Диагностика и лечение астмы у детей», в котором выделены различные фенотипы бронхиальной астмы с учетом возраста и пусковых факторов болезни. Для детей дошкольного возраста выделены 3 фенотипа, включая вирусиндуцированный фенотип, астму, индуцированную физической нагрузкой, и аллергический фенотип, характеризующийся наличием специфических $\operatorname{IgE}$ в сыворотке крови, определяемых in vitro или путем проведения кожных тестов [3]. Установление фенотипа бронхиальной астмы является ключевым для выбора оптимальной терапии, позволяет обеспечить дифференцированный подход к лечению и определяет прогноз заболевания [4]. До настоящего времени в России не проводились исследования, посвященные изучению распространенности аллергического и неаллергического фенотипа бронхиальной астмы среди детей дошкольного возраста, опубликованы лишь результаты единичных зарубежных исследований $[5,6]$.

Цель исследования: определить распространенность аллергической и неаллергической бронхиальной астмы у детей 3-6 лет, проживающих в городских условиях Алтайского края, и изучить спектр сенсибилизации.

\section{Характеристика детей и методы исследования}

Проведено одномоментное популяционное исследование распространенности аллергической и неаллергической бронхиальной астмы среди детей дошкольного возраста, проживающих в городских условиях Алтайского края. Исследование одобрено локальным независимым комитетом по этике при ФГБОУ ВО «Алтайский государственный медицинский университет» Минздрава России (протокол №11 от 17.10.2014) и согласовано с Министерством образования и науки Алтайского края. Исследование начато в сентябре 2015 г., закончено в апреле 2017 г.

Критерии включения:

- возраст детей 3-6 лет;

- посещение детского дошкольного учреждения;

- наличие информированного добровольного согласия родителей/законных представителей на участие детей в исследовании.

Исследование состояло из двух этапов: скринингового и клинического. Схема исследования представлена на рисунке. Скрининговый этап проведен
Камалтынова Елена Михайловна - д.м.н., доцент кафедры факультетской педиатрии с курсом детских болезней лечебного факультета Сибирского государственного медицинского университета, ORCID: 0000-0002-2234-5355 634050 Томск, Московский тракт, д. 2

в дошкольных образовательных учреждениях 5 из 11 городов Алтайского края (Барнаул, Рубцовск, Бийск, Камень-на-Оби, Новоалтайск). Методом жеребьевки из 356 учреждений дошкольного образования, расположенных в этих городах, было отобрано 78: 45 - в Барнауле, 8 - Новоалтайске, 10 - в Рубцовске, 5 - в Камне-на-Оби, 10 - в Бийске. На этапе скрининга устанавливали наличие симптомов бронхиальной астмы, используя опросник ISAAC [7]. Опросник выдавали родителям/законным представителям ребенка для самостоятельного заполнения. Участникам исследования необходимо было ответить на вопрос: «За последние 12 мес у Вашего ребенка были затрудненное хрипящее свистящее дыхание, свисты в грудной клетке?» При положительном ответе на этот вопрос ребенка относили к числу детей с симптомами бронхиальной астмы. Эти дети направлялись на клинический этап исследования для клинико-лабораторного обследования и подтверждения диагноза.

Процедуры клинического этапа проводились аллергологами-иммунологами и включали интервьюирование родителей/опекунов, клиническое обследование пациентов, лабораторные анализы кожное прик-тестирование с экстрактами бытовых, эпидермальных, пыльцевых и пищевых аллергенов и/или исследование уровня специфических IgE. Клинический этап исследования был проведен на базе ФГБОУ ВО «Алтайский государственный медицинский университет» Минздрава России в отделении аллергологии и иммунологии КГБУЗ «Клиническая детская больница №7» (Барнаул).

Диагноз бронхиальной астмы устанавливали на основании критериев международного согласительного документа Global Strategy for Asthma Management and Prevention (GINA, updated 2018) [8]. Аллергический фенотип бронхиальной астмы констатировали при положительном прик-тесте и/или при уровне специфических $\operatorname{IgE}$ в крови $>0,35$ кЕ/л как минимум к одному аллергену.

Процедура кожного прик-тестирования проводилась с 8 стандартизованными экстрактами аллергенов бытовой, пыльцевой, эпидермальной и пищевой групп (клещ домашней пыли Dermatophagoides pteronyssinus, эпителий кошки, эпителий собаки, пыльца березы, пыльца смеси луговых трав, пыльца полыни, коровье молоко, куриное яйцо) от Allergopharma, Германия. Положительный (гистамин 10 мг/мл) и отрицательный контроли использовали согласно клиническим рекомендациям [9]. Кожный тест считали положительным при формировании волдыря как минимум на 3 мм больше, чем отрицательный контроль. При отрицательном значении положительного контроля проводили исследование in vitro - определение 
специфических IgE в сыворотке крови. Определение уровня специфических $\operatorname{IgE~к~указанным~выше~ал-~}$ лергенам осуществляли в медицинской лаборатории «Гемотест» (Москва) методом иммунофлюоресценции на автоматическом анализаторе Phadia ImmunoCAP 250 («Phadia AB», «Thermo Fisher Scientific», Швеция).

Выявляли коморбидные аллергические заболевания. Аллергический ринит устанавливали на основании критериев ARIA (2008) [10]: при наличии $\geq 2$ симптомов заболевания (ринорея, затруднение носового дыхания, зуд в полости носа, повторяющееся чихание) продолжительностью $\geq 1$ ч при положительном прик-тесте и/или при уровне специфических $\mathrm{IgE}$ в крови $>0,35$ кЕ/л как минимум к одному аллергену. Диагноз атопического дерматита верифицировали на основании модифицированных диагностических критериев Hanifin и Rajka [11].

Статистический анализ. Расчет размера выборки проводился с помощью программы Epi Info версия 7.2.2.6. (CDC, США). Учитывая численность детского населения Алтайского края в возрасте 3-6 лет на момент исследования (92 350 детей), ожидаемую распространенность симптомов бронхиальной астмы среди детей 3-6 лет, равную 11\% (согласно данным опубликованных исследований), а также принимая во внимание заданную предельно допустимую ошибку $1,1 \%$ и $95 \%$ доверительный интервал, необходимый размер выборки был определен равным 3007. Исходя из того что ожидаемый возврат анкет может составить около 50\% было запланировано раздать 5306 экземпляров. Анализ полученных данных выполнен с использованием пакета статистических программ SPSS версия 17.0 (IBM SPSS, CША). Показатель распространенности бронхиальной астмы в популяции рассчитыва- ли по формуле: A/N·B, где A - число участников, ответивших «да» на вопросы анкеты; N - общее число участников, ответивших на вопросы анкеты на скрининговом этапе; В - число участников в процентном соотношении с подтвержденной бронхиальной астмой на клиническом этапе (адаптировано из [12]). Описание количественных переменных выполнено с указанием среднего арифметического и стандартного отклонения. Для оценки различий частотных признаков в группах использовали критерий $\chi^{2}$ Пирсона. Различия считали статистически значимыми при $p<0,05$.

\section{Результаты}

На этапе скрининга опросники ISAAC получили 5306 родителей (см. рисунок). Вернули заполненными 3255 (61,3\%) опросников, из них 50 были заполнены неполностью или неверно, в связи с чем были исключены из исследования. Таким образом, при анализе исходов исследования учитывались данные 3205 детей. Симптомы бронхиальной астмы были отмечены в 355 (11\%) из 3205 случаев. Родители 248 (69,8\%) пациентов с симптомами бронхиальной астмы подписали информированное согласие на участие детей в клиническом этапе исследования с проведением кожных прик-тестов и/или определением специфических IgE в сыворотке крови. Из 248 детей с симптомами бронхиальной астмы диагноз был верифицирован у 128 (51,6\%). Из них у 90 (70,3\%) детей диагностирован аллергический фенотип и у 38 (29,3\%) неаллергические фенотипы заболевания. Для анализа распространенности бронхиальной астмы и спектра сенсибилизации в зависимости от возраста все дети были разделены на 3 возрастные группы: 3-4 года, 5-6 лет и 3-6 лет. Демографическая и клиническая характеристика детей с бронхиальной астмой представлена в табл. 1.

Таблица 1. Демографическая характеристика пациентов, частота аллергического и неаллергического фенотипа бронхиальной астмы и коморбидные аллергические заболевания у детей 3-6 лет

Table 1. Demographics of the subjects, and the percentages of atopic and non-atopic phenotypes of bronchial asthma, and comorbid allergic diseases in children aged $3-6$ years

\begin{tabular}{|c|c|c|c|}
\hline \multirow{2}{*}{ Параметр } & \multicolumn{3}{|c|}{ Возрастная группа, годы } \\
\hline & $3-6$ & $3-4$ & $5-6$ \\
\hline Число пациентов, абс. (\%) & $128(100)$ & $60(46,9)$ & $68(53,1)$ \\
\hline Возраст, годы & $4,7 \pm 1,2$ & $3,6 \pm 0,5$ & $5,6 \pm 0,5$ \\
\hline \multicolumn{4}{|l|}{ Пол, абс. (\%) } \\
\hline мужской & $90(70,3)$ & $42(70)$ & $48(70,6)$ \\
\hline женский & $38(29,7)$ & $18(30)$ & $20(29,4)$ \\
\hline \multicolumn{4}{|c|}{ Фенотип бронхиальной астмы, абс. (\%) } \\
\hline аллергическая & $90(70,3)$ & $37(61,6)$ & $53(77,9)$ \\
\hline неаллергическая & $38(29,7)$ & $23(38,4)$ & $15(22,1)$ \\
\hline \multicolumn{4}{|c|}{ Коморбидные заболевания, абс. (\%) } \\
\hline аллергический ринит & $76(43,7)$ & $22(36,6)$ & $54(79,4)$ \\
\hline атопический дерматит & $30(23,4)$ & $11(18,3)$ & $19(27,9)$ \\
\hline
\end{tabular}




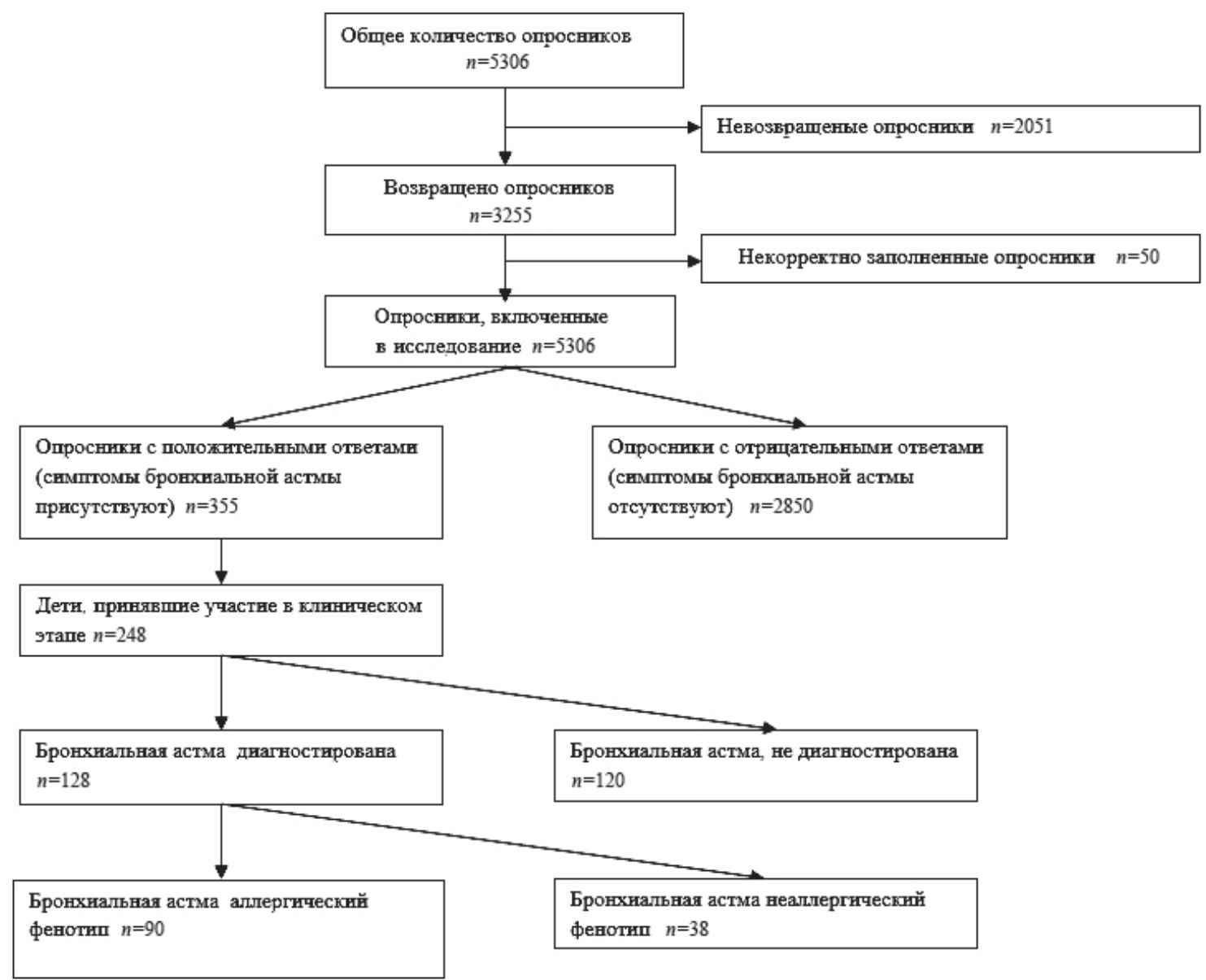

Рисунок. Схема исследования

Figure. Study diagram

Общая распространенность бронхиальной астмы среди городских детей в возрасте 3-6 лет составила $5,7 \%$ (табл. 2). Распространенность аллергической бронхиальной астмы достигала 4\%, неаллергической - 1,7\%. Распространенность аллергической бронхиальной астмы оказалась выше, чем неаллергической, во всех возрастных группах. С увеличением возраста отмечается увеличение распространенности аллергической бронхиальной астмы. Распространенность бронхиальной астмы среди мальчиков была выше, чем среди девочек - 6,6 и $4,7 \%$ соответственно.

При аллергологическом обследовании у 90 (70,3\%) из 128 детей выявлена сенсибилизация, из них у 38 (29,6 \%) - к одному аллергену, у 52 $(40,6 \%)$ - к 2 аллергенам и более (табл. 3). Сенсибилизация к 2 аллергенам и более в возрасте 5-6 лет отмечалась достоверно чаще, чем у детей 3-4 лет $(p=0,002)$. Сенсибилизация к ингаляционным аллергенам выявлена у $89(69,5 \%)$ детей, из них у 16 $(12,5 \%)$ определялось сочетание сенсибилизации к ингаляционным и пищевым аллергенам. Чаще всего обнаруживалась сенсибилизация к клещу домашней пыли Dermatophagoides pteronyssinus - у 55
$(42,9 \%)$ детей, пыльце березы - у 44 (34,3\%) и эпителию кошки - у 33 (25,7\%). Реже определялась сенсибилизация к пыльце луговых трав - у 10 (17,8\%) детей, к эпителию собаки - у 14 (10,9\%), пыльце полыни - у 17 (13,2\%). У 19 (21,1\%) детей установлена сенсибилизация к пищевым аллергенам, из них у 13 $(10,1 \%)$ - к белку куриного яйца, у $12(9,3 \%)$ - к коровьему молоку.

\section{Обсуждение}

Распространенность бронхиальной астмы среди детей 3-6 лет согласно результатам нашего исследования составила 5,7\%. При этом распространенность Таблица 2. Распространенность аллергической и неаллергической бронхиальной астмы среди детей 3-6 лет Table 2. Prevalence of atopic and non-atopic phenotypes asthma in the children aged 3-6 years

\begin{tabular}{cccc}
\hline $\begin{array}{c}\text { Возраст, } \\
\text { годы }\end{array}$ & \multicolumn{3}{c}{ Распространенность бронхиальной астмы, \% } \\
оба фенотипа & аллергическая & неаллергическая \\
\hline $3-6$ & 5,7 & 4,0 & 1,7 \\
\hline $3-4$ & 5,1 & 3,1 & 2,0 \\
$5-6$ & 6,3 & 4,9 & 1,4 \\
\hline
\end{tabular}


Таблица 3. Спектр сенсибилизации у детей 3-6 лет с бронхиальной астмой, абс. (\%) Table 3. Sensitization profile in the children aged 3-6 years with asthma, абс. (\%)

\begin{tabular}{|c|c|c|c|c|c|}
\hline \multirow{2}{*}{$\begin{array}{c}\text { Аллергены (источники аллергенов) } \\
\text { и виды сенсибилизации }\end{array}$} & \multirow{2}{*}{$\begin{array}{c}\text { Всего детей, } \\
n=128\end{array}$} & \multicolumn{2}{|c|}{ Возраст детей, годы } & \multirow{2}{*}{ Критерий $\chi^{2}$} & \multirow{2}{*}{$p$} \\
\hline & & $3-4, n=60$ & $5-6, n=68$ & & \\
\hline Ингаляционные & $73(57)$ & $32(53,3)$ & $41(60,3)$ & 0,070 & 0,427 \\
\hline Пищевые & $1(0,8)$ & $1(1,6)$ & 0 & - & - \\
\hline Ингаляционные и пищевые & $16(12,5)$ & $5(8,3)$ & $11(16,1)$ & 0,118 & 0,180 \\
\hline Моносенсибилизация & $38(29,6)$ & $21(35)$ & $17(25)$ & 0,109 & 0,210 \\
\hline Полисенсибилизация* & $52(40,6)$ & $16(26,7)$ & $36(52,9)$ & 0,258 & 0,002 \\
\hline $\begin{array}{l}\text { Клещ Dermatophagoides pteronys- } \\
\text { sinus }\end{array}$ & $55(42,9)$ & $20(33,3)$ & $35(52,9)$ & 0,180 & 0,030 \\
\hline Кошка & $33(25,7)$ & $10(16,6)$ & $23(33,8)$ & 0,192 & 0,026 \\
\hline Собака & $14(10,9)$ & $6(10)$ & $8(11,7)$ & 0,028 & 0,740 \\
\hline Береза & $44(34,3)$ & $17(28,3)$ & $27(39,7)$ & 0,119 & 0,176 \\
\hline Смесь луговых трав & $10(7,8)$ & $3(5)$ & $7(10,3)$ & 0,119 & 0,265 \\
\hline Полынь & $17(13,2)$ & $3(5)$ & $14(20,5)$ & 0,223 & 0,009 \\
\hline Коровье молоко & $12(9,3)$ & $4(6,7)$ & $8(11,7)$ & 0,087 & 0,323 \\
\hline Яйцо & $13(10,1)$ & $5(8,3)$ & $8(11,7)$ & 0,050 & 0,100 \\
\hline
\end{tabular}

* - сенсибилизация $\mathrm{K} \geq 2$ аллергенам.

аллергической бронхиальной астмы преобладала над неаллергической - 4 и 1,7\% соответственно. С увеличением возраста детей повышается удельный вес аллергической бронхиальной астмы. Большинство детей сенсибилизированы к 2 аллергенам и более, чаще всего отмечалась сенсибилизация к ингаляционным аллергенам - клещу домашней пыли Dermatophagoides pteronyssinus, пыльце березы и эпителию кошки.

Конечные выводы нашего исследования сопоставимы с ранее опубликованными данными. Согласно нашим результатам, аллергический фенотип имеют 70,3\% детей с бронхиальной астмой в возрасте 3-6 лет. По данным исследования, проведенного в Дании, аллергический фенотип имеют 67,7\% детей с бронхиальной астмой в возрасте от 0 до 15 лет [13]. Согласно результатам, полученных в Индии, аллергический фенотип выявлен у 56,6\% детей с бронхиальной астмой в возрасте 5-18 лет [14], а по данным тайваньских ученых, аллергическая бронхиальная астма диагностирована у $57,1 \%$ детей в возрасте 3-6 лет [15].

Мы установили, что чаще всего (в 42,9\% случаев) дети с бронхиальной астмы сенсибилизированы к клещам домашней пыли (клещ Dermatophagoides pteronyssinus), что соответствует сведениям литературы. Так, по данным американских исследователей, 57,7\% детей 4-16 лет, госпитализированных в связи с обострением бронхиальной астмы, сенсибилизированы к этому клещу [6]; по результатам исследований, проведенных в Китае и на Тайване, сенсибилизация к Dermatophagoides pteronyssinus установлена у 50,6\% больных детей [16] и у $35,8 \%$ больных детей 3-6 лет [15].
Вторым по значимости ингаляционным аллергеном при бронхиальной астме у детей дошкольного возраста, согласно нашим данным, является эпителий кошки, сенсибилизация к которому выявлена у $25,7 \%$ детей. Полученные результаты сопоставимы с данными других исследований, согласно которым к аллергенам кошки сенсибилизированы $19 \%$ (Китай) и $12 \%$ (Шри-Ланка) детей с бронхиальной астмой $[16,17]$.

Ограничения исследования. В нашем исследовании не принимали участие дети, проживающие в сельской местности, в то время как, по данным литературы, распространенность аллергических заболеваний среди сельского и городского населения различна $[18,19]$. Таким образом, остается неизвестной распространенность бронхиальной астмы среди детей дошкольного возраста Алтайского края, проживающих в сельской местности. При проведении скрининга было выдано 5306 анкет, но только 3205 (60\%) из них были включены в анализ, что также могло повлиять на полученные результаты. В исследовании не принимали участие дети, не посещающие детские учреждения; согласно сведениям регионального Министерства образования и науки, в 2015-2016 гг. такие дети составляли 6\%. На результаты работы, вероятно, повлиял и отказ $30,2 \%$ родителей от участия их детей в клиническом этапе исследования.

\section{Заключение}

В результате анализа данных выявлена высокая распространенность бронхиальной астмы среди детей 3-6 лет, проживающих в городских условиях Алтайского края - 5,7\%. Распространенность аллергической 
бронхиальной астмы преобладает над неаллергической - 4 и 1,7\% соответственно. Большинство детей сенсибилизированы к 2 аллергенам и более, наиболее часто отмечается сенсибилизация к ингаляционным аллергенам - клещу домашней пыли Dermatophagoides pteronyssinus, пыльце березы и эпителию кошки.

\section{ЛИТЕРАTУPA (REFERENCES)}

1. Global Initiative for Asthma. Global Strategy for Asthma Management and Prevention. Update 2016. Available from: www.ginasthma.com (the link is active on 3.11.2018).

2. Anandan C., Nurmatov U., van Schayck O.C., Sheikh A. Is the prevalence of asthma declining? Systematic review of epidemiological studies. Allergy 2010; 65: 152-167. DOI: 10.1111/j.1398-9995.2009.02244.X

3. Bacharier L.B., Boner A., Carlsen K.-H., Eigenmann P.A., Frischer T., Götz M. et al. Diagnosis and treatment of asthma in childhood: a PRACTALL consensus report. Allergy 2007; 63(1): 5-34. DOI: 10.1111/j.1398-9995.2007.01586.x

4. Froidure A., Mouthuy J., Durham S.R., Chanez P., Sibille Y., Pilette $C$. Asthma phenotypes and IgE responses. Eur Respir J 2016; 47(1): 304-319. DOI: 10.1183/13993003.01824-2014

5. Lawson J.A., Chu L.M., Rennie D.C., Hagel L., Karunanayake C.P., Pahwa P. et al. Prevalence, risk factors, and clinical outcomes of atopic and nonatopic asthma among rural children. Ann Allergy Asthma Immunol 2017; 118(3): 304-310. DOI: $10.1016 /$ j.anai.2016.11.024

6. Beck A.F., Huang B., Kercsmar C.M., Guilbert T.W., Mc Linden D.J., Lierl M.B. et al. Allergen sensitization profiles in a population-based cohort of children hospitalized for asthma. Ann Am Thorac Soc 2015; 12(3): 376-384. DOI: 10.1513/ AnnalsATS.201408-3760C

7. Гаврилов С.М. Стандартизированные эпидемиологические исследования аллергических заболеваний у детей. (Адаптация программы «Международное исследование астмы и аллергии «ISAAC» в России). Пособие для врачей. М., 1998; 30 [Gavrilov S.M. Standardized epidemiological studies of allergic diseases in children. (Adaptation of the program "International Study of Asthma and Allergy" ISAAC “in Russia). Manual for doctors. Moscow, 1998; 30. (in Russ)]

8. Global Initiative for Asthma. Global strategy for Asthma management and prevention. Global Initiative for Asthma (updated 2018) 2018. https://ginasthma.org/2018-gina-report-global-strategy-for-asthma-management-and-prevention. (the link is active on 3.11.2018).

9. Heinzerling L., Mari A., Bergmann K.C., Bresciani M., Burbach G., Darsow U. et al. The skin prick test - European standards. Clin Transl Allergy 2013; 3(1): 3. DOI: 10.1186/20457022-3-3

10. Bousquet J., Khaltaev N., Cruz A.A., Denburg J., Fokkens W.J., Togias A. et al. Allergic Rhinitis and its Impact on Asthma (ARIA) 2008 update (in collaboration with the World Health Organization, GA(2)LEN and AllerGen). Allergy 2008; 63(86): 8-160. DOI: 10.1111/j.1398-9995.2007.01620.x

Поступила: 27.09.18

11. Федеральные клинические рекомендации по диагностике и лечению атопического дерматита. Под ред. P.М. Хаитова, Н.И. Ильиной М.: Фармарус Принт Медиа, 2014; 124. [Federal clinical guidelines for the diagnosis and treatment of atopic dermatitis. R. Haitov, N. Ilina (eds). Moscow: Pharmarus Print Media, 2014; 124. (in Russ)]

12. Федорова О.С. Распространенность пищевой аллергии в мировом очаге описторхоза. Бюллетень сибирской медицины. 2010; 5: 102-108. [Fedorova O.S. Food allergy prevalence in children of opisthorchiasis world region. Bûlleten' sibirskoi meditsiny (Bulletin of Siberian Medicine). 2010; 5: 102-108. (in Russ)]

13. Hoffmann-Petersen B, Høst A., Larsen K.T., Bergstein K.R., Thomsen M.L., Braendholt V., Halken S. Prevalence of IgE sensitization in Danish children with suspected asthma. Pediatr Allergy Immunol 2013; 24(8):727-733. DOI: 10.1111/ pai. 12133

14. Raj D., Lodha R., Pandey A., Mukherjee A., Agrawal A., Kabra S.K.; New Delhi Childhood Asthma Study Group. Aeroallergen sensitization in childhood asthmatics in northern India. Indian Pediatr 2013; 50(12): 1113-1118.

15. Su Y.T., Yang Y.N., Li Y.C., Tsai C.C., Chen L.M., Lin Y.C. et al. Age-dependent distribution of the atopic phenotype and allergen sensitization among asthmatic children in southern Taiwan. Asian Pac J Allergy Immunol 2016; 34: 206-211. DOI: $10.12932 / A P 0475$

16. Li J., Huang Y., Lin X., Zhao D., Tan G., Wu J. et al. and for China Alliance of Research on Respiratory Allergic Disease (CARRAD). Influence of degree of specific allergic sensitivity on severity of rhinitis and asthma in Chinese allergic patients. Respiratory Research 2011; 12: 95. DOI: 10.1186/14659921-12-95

17. Senanayake M.P., de Silva R., Jayamanna M.D., Jayasinghe J.A., Ratnayaka D., Jayasuriya $V$. et al. Identification of aero-allergen sensitization in children seeking treatment for bronchial asthma at a tertiary care hospital for children in Sri Lanka. Ceylon Med J 2014; 59(3): 89-93. DOI: 10.4038/cmj.v59i3.7469

18. Lee S.Y., Kwon J.W., Seo J.H., Song Y.H., Kim B.J., Yu J. et al. Prevalence of atopy and allergic diseases in Korean children: associations with a farming environment and rural lifestyle. Int Arch Allergy Immunol 2012; 158(2): 168-174. DOI: $10.1159 / 000330820$

19. Hajavi J., Tolide-ie H.R., Rastgoie Chavoshlu S. et al. Do rural and urban children have different prevalence of allergic disorders in Gonabad? Horizon Med Sci 2012; 18(2): 21-26.

Received on: 2018.09.27

Конфликт интересов:

Авторы данной статьи подтвердили отсутствие конфликта интересов и финансовой поддержки, о которых необходимо сообщить.

Conflict of interest:

The authors of this article confirmed the lack of conflict of interest and financial support, which should be reported. 